\title{
Correction to: Recent Clinical and Epidemiological Studies of Itai-Itai Disease (Cadmium-Induced Renal Tubular Osteomalacia) and Cadmium Nephropathy in the Jinzu River Basin in Toyama Prefecture, Japan
}

\author{
Keiko Aoshima
}

\section{Correction to:}

Chapter 2 in: S. Himeno, K. Aoshima (eds.), Cadmium Toxicity, Current Topics in Environmental Health and Preventive Medicine, https://doi.org/10.1007/978-981-13-3630-0

This chapter was inadvertently published with incorrect data in the abstract. Details are as follows:

Incorrect: $<1 \mathrm{mg} / \mathrm{g}$ creatinine

Correct: $<1 \%$ 